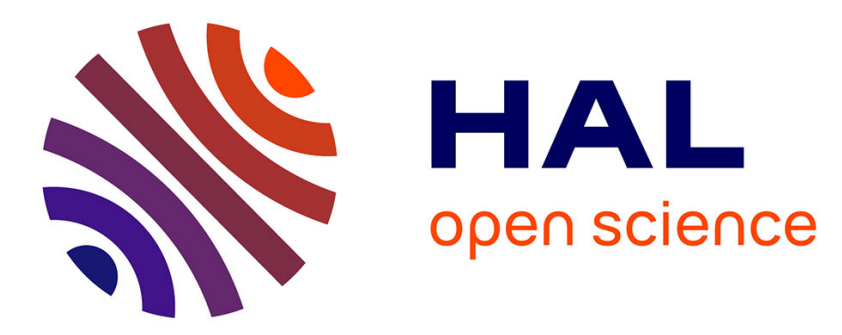

\title{
Goal orientations and conceptions of the nature of sport ability in children: A social cognitive approach
}

Philippe Sarrazin, Stuart K. Biddle, Jean-Pierre Famose, François Cury, Kenneth Fox, Marc Durand

\section{- To cite this version:}

Philippe Sarrazin, Stuart K. Biddle, Jean-Pierre Famose, François Cury, Kenneth Fox, et al.. Goal orientations and conceptions of the nature of sport ability in children: A social cognitive approach. British Journal of Social Psychology, 1996, 35 (3), pp.399-414. 10.1111/j.2044-8309.1996.tb01104.x . hal-00387221

\section{HAL Id: hal-00387221 \\ https://hal.science/hal-00387221}

Submitted on 25 May 2009

HAL is a multi-disciplinary open access archive for the deposit and dissemination of scientific research documents, whether they are published or not. The documents may come from teaching and research institutions in France or abroad, or from public or private research centers.
L'archive ouverte pluridisciplinaire HAL, est destinée au dépôt et à la diffusion de documents scientifiques de niveau recherche, publiés ou non, émanant des établissements d'enseignement et de recherche français ou étrangers, des laboratoires publics ou privés. 


\section{Goal orientations and conceptions of the nature of sport ability in children: A social cognitive approach}

Philippe Sarrazin* ${ }^{\dagger}$

Laboratoire de recherche en STAPS, University of Paris XI-Orsay, Paris, France

Stuart Biddle*

Schorl of Education, University of Exeter, $U K$

Jean Pierre Famose and Francois Cury

Lahuratuire de recherche en STAPS, University of Paris XI-Orsay, Paris, France

Kenneth Fox

School of Education, University of Exeter, UK

Marc Durand

Centre d'Optimisation de la performance Motrice, University of Montpellier I, Montpellier, France

Contemporary research in the social psychology of sport has used Nicholls' $(1984,1989)$ social cognitive theory of goal orientations and motivation in order to gain a better understanding of cognitive, affective and behavioural aspects of sport participation. Success can be defined in at least two different ways that lead to two major goal orientations (task/mastery and social comparison), but little is known about why or how such goals may develop, although preliminary research in education links goals to conceptions about the nature of academic ability (i.e. Intelligence). Using a similar notion, we studied conceptions of athletic ability by assessing children's representations of sport ability. Two studies were conducted with children and youth in England and France. Initial findings suggested that the methods adopted by Dweck \& Leggett (1988) in education, while showing some links between goals and beliefs, are not wholly applicable to sport. In using a more comprehensive measure of sport ability conceptions, we observed clear relationships between a social comparison goal and a conception of athletic ability as a 'gift' and being 'general', and between a task mastery goal and the conception of athletic ability as being incremental and determined by learning. We develop and discuss the meaning of the causal links that unite goals and ability conceptions, as well as the likely impact of such conceptions on motivation.

* Requests for reprints to eicher Philippe Sarrazin, 28, rue L. de Vinci, 26000 Valence, France or Stuart Biddle, School of iducation, University of Exeter, Exeter EX12LU, UK.

E 
The social psychological study of sport has increased in recent years as issues such as the health benefits of physical activity and the effects of competition on children have become more prominent. As far as sport motivation is concerned, a central construct that has been identified is that of self-perceptions of ability and related constructs such as self-efficacy or perceived competence (Roberts, 1992). Perceived ability has been shown to be associated with initial as well as continued or discontinued involvement in sport (e.g. Burton \& Martens, 1986; Gould, Feltz, Horn \& Weiss, 1982; Roberts, Kleiber \& Duda, 1981). Perceived ability is also important in decision making in the face of task difficulty (Famose, Sarrazin, Cury \& Durand, 1993), as well as for perseverance and effort in sport (Famose, Sarrazin \& Cury, 1993).

Parallel to these findings, Nicholls' developmental studies in the academic field have brought to light semantic variations in the ability concept (Nicholls, 1989; Nicholls \& Miller, 1984; Nicholls, Patashnick \& Mettetal, 1986). A distinction is made, in particular, between two significant approaches that are closely connected to cognitive develop ment and to the differentiation of the concepts of chance, effort and task difficulty. The first conception of ability - sometimes referred to as less differentiated-is associated with concepts of general mastery, progress and effort. The person who uses this approach will feel more able as they feel that they are making progress and mastering objects through personal effort. The second conception of ability is more mature and appears at about 11-12 years of age. This is the more differentiated conception of ability since the concept of effort is no longer equated with that of ability. The individual now conceives of ability as a capacity that limits the effect of effort on performance.

Recent work in achievement motivation, using a social cognitive perspective, considers the search for competence as the main focus of interest for individuals in achievement situations. This quest can appear through orientations towards two differen goals, referring in each case to one or the other of the two approaches to ability described above. In one case, the feeling of competence rests on self-referenced criteria and on a process of comparison over time; learning, mastery and personal improvement are experienced as success and are satisfying in themselves. This is referred to as 'task involvement' (Nicholls, 1984, 1989). Alternatively, the feeling of competence can also be subordinated to external criteria and to a process of normative comparison with a group of peers. Demonstration of superiority becomes the dominant focu for the definition of a successful experience. This is referred to as 'ego involvement' (Nicholls, 1984, 1989).

Individuals are thought to hold relatively stable dispositions towards these goals and hence are thought to adopt a 'mastery' (Roberts, 1992), 'task' (Duda, 1992) or 'learning' goal (Dweck, 1986) when success is defined in self-referent terms, and a 'competitive' (Roberts, 1992), 'ego' (Duda, 1992) or 'performance' goal (Dweck, 1986) when success i defined primarily in normative terms. This latter goal we will call the social comparison goal. These two goals, or tendencies, have been shown to be orthogonal (Nicholls, 1989); Duda, 1992), thus it is possible for one individual to have a dominant oricntation, or to be at the same time strongly or weakly oriented in both (Fox, Cioudas, Biddle, Duclu \& Armstrong, 1991).

It has been suggested that people's thoughts, sensations and behaviour in uchievement contexts are rational expressions of their domintant goals (Nicholls, 1989), 1992). Por example, low perceived ability has no adverse conseguences on the involvement and perseverance of those individuals who pursue a mastery goal (see Duda, 1992; Famose, 1990, 1991; Famose et al., 1993; Nicholls, 1989; Roberts, 1992), whereas maladaptive motivational responses have been reported for children with low perceived competence adopting a social comparison goal (Goudas, Biddle \& Fox, 1994).

According to Nicholls (Nicholls, 1989,1992 ; Nicholls et al. 1986), the two conceptions of ability underlying the goals are rather general in that they can apply to many different situations (e.g. intellectual, musical, physical etc.). They refer to the understanding of immediate or proximal causes of performance, such as the relative contribution of effort and ability. Nevertheless, they say nothing about people's representations of the longer term transformations of competence, or how these goals are developed in the first place. This has given rise to recent research in the study of achievement goals in the classroom, such as Dweck's studies of the 'implicit theories of intelligence' (Dweck \& Bempechat, 1983 Dweck \& Elliott, 1983; Dweck \& Leggett, 1988) and Nicholls' developmental work on the 'conceptions of intelligence' (Nicholls, 1989, 1992; Nicholls et al. 1986). The aim of the latter has been to make clear the participants' representations concerning either their longer term developmental capacity of ability (is it stable or incremental? Is it generic or specific?) or its determinants (is it a natural gift and/or a product of learning?).

Similarly, Dweck and her colleagues (e.g. Dweck \& Leggett, 1988; Elliott \& Dweck, 1988 ) were interested in finding out why some children demonstrated a maladaptive, or helpless, pattern of behaviour after classroom failure while others reacted with more adaptive and mastery oriented responses. Dweck and Leggett (1988) reported that:

our efforts to explain this phenomenon led us to the more general conceptualisation of goals. We proposed that the goals individuals are pursuing create the framework within which they interpret and react to events (p. 256)

Dweck suggested that children who believed that their intelligence was mainly a fixed entity ('entity theory') were more likely to choose a performance (social comparison) goal as one way of demonstrating that entity. On the other hand, those choosing a learning (mastery) goal were more likely to believe that intelligence is a changeable and malleable quality ('incremental theory') since a learning goal allowed for the development of intelligence.

This paper will report on research into the conception of the nature of athletic ability, drawing on perspectives of both Dweck and Nicholls. Consequently, the research concerns the beliefs of individuals regarding the possibilities of developing ability over time and its determinants. The starting point of our work was a now rather well recognized 'objective' description of sport competence, based on the notions of aptitude (basic qualities), skills (capacity for a specific task or group of tasks) and performance (Ackerman, 1990; Fleishman, 1964; Famose \& Durand, 1988). Skills are defined as resulting from specific learning, are easily changeable, and therefore much less determined by genetic factors than aptitudes (Schmidt, 1982).

The purpose of this paper, therefore, is to report on two studies, involving nearly 500 chil dren from two countries, investigating the links between goal orientations and conceptions of sport ability. Although two countries were involved, this was to increase the external validity of findings rather than to test for cross-cultural effects. No differences were expected between countries. Specifically, it was hypothesized that goals reflecting learning and mastery will be assoc liated with sport ability conceprions that reflect change and instability. 


\section{STUDY 1}

Links between goals and conceptions of ability have been proposed by Dweck and Nicholls, as discussed. As a first step to identify similar links in sport contexts, Study 1 sought to replicate methods reported by Dweck and her colleagues (Dweck \& Leggett, 1988; Elliott \& Dweck, 1988), but in the context of sport.

Sample and procedures

\section{Method}

Girls and boys $(N=194)$ aged $11-12$ years took part in this investigation. This age range represents the time at which children develop mature conceptions of ability. All of the children attended schools in a city in the at which children develop mature conceptions of ability. All of the children attended schools in a city in the
south-west of England and they were considered to be a reasonable cross-section of pupils from the city. All children were involved in sport through school physical education, although no assessment was made of their voluntary sport involvement.

Each child completed a psychological inventory pack as part of a larger study. As far as the present study is concerned, the inventory, modified from the recommendations of Dweck and Henderson (no date), included questions on achievement goal choice and perceptions of the nature of sport ability. In addition, the inventory included the Task and Ego Orientation in Sport Questionnaire modified for English schoolchildren
(TEOSQ; see Duda, Fox, Biddle \& Armstrong, 1992).

\section{Instrumentation}

Gral chuice. The children were asked to select their preferred goal in sport contexts. On the recommendation of Dweck and Henderson, two types of performance (social comparison) goal were given. One referred to an easy (no risk) performance goal and the other to a challenging performance goal. Two of thc four choices are for easy performance goals as Dweck and Henderson suggest that such choices are low in social desirability; thus having two statements makes it appear a more viable option. For the purposes of analysis, however, participants choosing either of these statements were classified as choosing an easy performance goal. Finally, a learning (mastery) goal was presented as the orher goal choice.

Goal orientations. The TEOSQ was used to assess task (mastery) and ego (social comparison) goal orientations. It consists of 13 items preceded by the stem I I feel successful in sport when .... For example, a mastery item asks the degree to which the respondent feels successful 'when I try hard', whereas a social comparison item assesses the degree of feelings of success 'when I win'. Satisfactory psychometric properties exist for the TEOSQ across diverse international samples (Biddle, Akande, Vlachopoulos \& Fox, in press; Duda et al. 1992; Goudas et al., 1994).

Sport Incremental Ability Siale (SIAS). Again, a modification of procedures from Dweck and Henderson was adopted. The SIAS was a reworded version of Dweck and Henderson's measure of theories of intelligence. In place of the word intelligence, we substituted the term 'sport ability'. The children stated their level of agreement on three six-point scales that referred to the extent that sport ability was fixed (entity) or increnter Scores were averaved across the three scales giving a range from 6 (strong incremental beliefs) to 1 (stron fixed/entity beliefs). The three items were: (1) 'you have a fxed amount of sports ability and you can't reang do much to change it'; (2) 'your sports ability is something about you that you can't chand you can ' $\mathrm{treally}$ do much to hou you can learn new things in sport but you can't really change your basic sports ability'. Internal consistency
of the scale was satisfactory (Cronbach's alpha $=.71$ ).

\section{Results and Discussion}

There was no significant difference between boys and girls on the SIAS score and so data for these two groups were merged. The sample had an overall mean score of 3.55 $(\mathrm{SI})=1.04)$, showing a normally distributed set of scores.
Table 1. Goal choice and SIAS group cross-tabulation, showing percentages from Study 1, with comparison data from Dweck \& Leggett (1988)

\begin{tabular}{|c|c|c|c|}
\hline \multirow[b]{2}{*}{$\begin{array}{l}\text { Study and } \\
\text { 'theory' } \\
\end{array}$} & \multirow[b]{2}{*}{ Learning } & \multicolumn{2}{|c|}{ Goal choice } \\
\hline & & $\begin{array}{l}\text { Performance } \\
\text { (easy) }\end{array}$ & $\begin{array}{l}\text { Performance } \\
\text { (challenging) }\end{array}$ \\
\hline \multicolumn{4}{|c|}{ Study $1(N=194)$} \\
\hline Fixed & 42.0 & 26.0 & 32.0 \\
\hline Incremental & 55.3 & 12.8 & 31.9 \\
\hline \multicolumn{4}{|c|}{ Dweck \& Leggett (1988) $(N=63)$} \\
\hline Entity (fixed) & 18.2 & 31.8 & 50.0 \\
\hline Incremental & 60.9 & 29.3 & 9.8 \\
\hline
\end{tabular}

To compare results with those from Dweck \& Leggett (1988), scores on the SIAS were used to create two groups of participants: those scoring above 3.5 were classified as having 'incremental' beliefs, and those below 3.5 were those with 'fixed' beliefs about sport ability. The three goal choices (learning, easy performance, challenging performance) were then used in a 2 (fixed vs. incremental SIAS group) $\times 3$ (goal choice) chi square (see Table 1). Results showed that goal choice was related to fixed/incremental belief $\left(\chi^{2}=6.20, p<.04\right)$, with those choosing a learning goal more likely to have incremental beliefs about sport ability and those preferring an easy performance goal more likely to have fixed beliefs. However, the differences for those in the learning goal category were much smaller than those reported by Dweck \& Leggett (1988) and the trends for the two performance goals were reversed from their study. Figures from Dweck \& Leggett (1988) are included in Table 1 for comparison.

The results of the chi-square analysis allowed a direct comparison with results from Dweck \& Leggett (1988). In addition, however, a one-way ANOVA was computed on continuous SIAS scores using the three goal choices as the independent variable. A significant difference was found $(F(2,191)=3.40, p<.04)$. Post boc Scheffé tests showed that children choosing the learning goal were significantly higher on SIAS scores than those choosing either of the two performance goals. These high scores reflected more incremental beliefs. Dweck \& Leggett's hypothesis that learning goals are associated with incremental beliefs is therefore supported in a different achievement domain.

The use of dichotomous goals, which the children had to choose between, has been criticized (Nicholls, 1992) and so further analyses were conducted with scores from the TEOSQ. However, there was no significant correlation between task and SIAS $(r=.01)$, although a significant but small correlation between ego goal scores and SIAS was found $(r=-.13, p<.05)$.

The latter results suggest that the relationship between conceptions of sport ability and goals is small. Forcing children to choose one goal when they might endorse morc than one may, therefore, provide exaggerated links. Consecuently, Study 2 sought to extend this research. 
Study 1 was a direct test of the propositions put forward by Dweck \& Leggett (1988), but in a sport rather than a classroom context. However, the methodology advocated by Dweck \& Leggett (1988) is weak on two fronts. First, asking the children to choose a goal, rather than state their degree of endorsement of several goals, is contrary to goal perspectives theory (see Duda, 1992). Second, the conception of sport ability may need broadening to be more in line with views expressed by Nicholls (1992). It is likely that if conceptions of sport ability are related to achievement goals, the results reported so far while indicative of a link, may be restricted by the narrow way that sport ability beliefs have been operationally defined. As Nicholls (1992) has said:

we cannot effectively study children's conceptions of intelligence or sport competence by simply asking

(in the fashion of Dweck and Bempechat, 1983) whether such skills are changeable or nor. Intelligence

can have many referents ... it commonly refers to genetic potential, realized potential, and displayed

competence. And, each of these can be thought of with respect to different types of intellectual skill.

When studying concepts of intelligence, we need to be able either to discern or to control the many possible senses of change and intelligence the child is employing (p. 45).

To investigate these more diverse senses of ability conceptions, we referred to the 'scientific' and 'lay' conceptions of sport ability. The 'scientific conception' is based on Fleishman's work (see also Ackerman, 1990; Schmidt, 1982). Fleishman (1964) distinguishes between abilities and skills, with the latter seen to evolve from learning and to be specific to a task or group of tasks. Abilities are relatively stable at adulthood, sometimes genetically determined and rather general. They limit the effect of learning on performance.

These notions of skill and ability are widely accepted. In addition, the notions of stable and incremental beliefs, supported by Dweck, were seen to be consistent with a multifaceted view of sport ability, so were kept for further analyses.

In addition to the scientific view of ability, there is also support for these constructs through a 'lay conception' of sport ability. Some people in sport, such as journalists and spectators, often convey the image that their ability is a 'gift' or is natural, whereas others reflect achievement produced more through effort and work. Sports participants, for example, sometimes convey the image of hard work, sacrifice and self-denial (i.e success is produced through effort), whereas others refer to the ease of the task or ' giftedness' (i.e. success results from 'given' talent).

From the above discussion, and that on goal orientations, it seemed reasonable to hypothesize that (a) children oriented towards a social comparison goal will view athletic ability more in terms of stability, generality, and the fact that sport ability is a 'natural gift'; (b) children who are mastery oriented will have a representation of athletic ability that tends more towards instability, specificity and a product of learning.

Participants

\section{Method}

School pupils ( $N=304 ; 184$ girls, 120 boys) aged 11 to 17 years $(M=14.0, S D=1.62)$ from a school in Paris, France took part in the study. The pupils represented all seven secondary school years.

Procedures

Questionnaires were completed in class time at the end of a normal lesson. The pupils were informed that the purperse of the questionnaire was to gain a better understanding of young people's motivation in sport, when they felt successful in sport, and what conception they had of competence in sport. The questionnaire was anonymous and took approximately 20 minutes to complete. All participants were involved in sport through school physical education, but no assessment was made of voluntary sport involvement.

\section{Instruments}

Gral orientations. The pupils were administered the French version of the Perception of Success Questionnair (POSQ) developed for sport by Roberts \& Balague (1989; see also Treasure \& Roberts, 1994). The POSQ consists of 12 items in two independent subscales and measures individual differences in the tendency to emphasize social comparison (ego) (e.g. 'I beat other people', 'I do better than my opponents') and/or task mastery and learning in sport (e.g. 'I overcome difficulties', 'I do my best'). This questionnaire is conceptually very similar to the TEOSQ and has been validated with children in France by Durand, Cury, Sarrazin \& Famose (in press). Pupils responded to the stem, 'I feel really successful in sport when . . .', and five-point scales wer used, anchored by 'strongly disagree' (1) and 'strongly agree' (5).

Conceptions of the nature of atbletic ability. We had intended to ask the children to indicate their conception of athletic ability by choosing between whether sport ability was the result of being a 'gift' or the result of 'learning', whether it was 'stable' or 'unstable/incremental', and 'general' or 'specific'. However, in the course of interviews conducted with the pupils, it became apparent that some of them found it awkward to exclude one conception for another, since both could equally contribute to athletic ability. This representation, similar to the 'scientific' analysis by Ackerman (1990) and Fleishman (1964), deserved to be taken into account. Consequently, we replaced the dichotomous format (elsewhere criticized by Nicholls, 1992) with a five-point agree/disagree scale for each conception of ability. Preliminary investigation with 10 girls and 10 boys took place in order to verify the different dimensions of the nature of ability. Subjects were then able to choose among several formulations (to which they felt free to add their own) those that best clarified the concepts of 'gift', 'stable', 'general' etc. This procedure allowed us to construct appropriate irems for the Conception of the Nature of Athletic Ability Questionnaire (CNAAQ). Six subscales corresponding different representations of the nature of ability were proposed: 'stable' (four items, e.g. 'One has a certa level in sport, and there is not much one can do to change that'); "incremental' (three items, e. 'In sport, one works hard and often, one necessarily progresses'); ' natural gift' (four items, e. 'To be good in sport, one must be born with basic qualities that permit success in that area') 'learning' (four items, e ' succeed in sport, one must learn techniques, movements, strategies and rehearse them over and over) 'general' (three items, e. 'In principle, if one is good at one sport, one is good at almest every and over if they are not alike'); 'specific' (three items, e.g. 'a person who has a good level in one sporr may not succeed in orhers') Responses to the CNAAQ were made on five-point scales anging fom 'strongly disagec' (1) 'strongly atyree' (5).

\section{Results and Discussion}

The psychometric properties of the different scales used in the study were assessed. Items from the POSQ and CNAAQ questionnaires were analysed separately using exploratory factor analysis and Cronbach's alpha coefficient for the assessmen of internal consistency. Factors were selected if they possessed an eigenvalue greater than 1 and accounted for at least 5 per cent of the variance. Also, only factor loadings exceeding .40 were considered. Varimax and oblimin rotations were calculated each time; they produced similar results.

\section{Goal orientation}

For the POSQ, two factors were found and the 12 items fell into the two categorics hypothesized: social comparison and mastery, and were independent factors (interfitctor 
correlation $=-.14$ ) similar to prior research (e o. Duda et al., 1992; Fox et al., 1994; Treasure \& Roberts, 1994). Both subscales were found to be internally consistent using Cronbach's alpha (social comparison $\alpha=.76$; mastery $\alpha=.75$ ).

Conceptions of the nature of atbletic ability

Factor analysis of the 21-item CNAAQ revealed six factors, as hypothesized, with five of the six having acceptable internal consistency, using Cronbach's alpha: 'learning-induced' $(\alpha=.75)$, 'general ability' $(\alpha=.82)$, 'gift-induced' $(\alpha=.88)$, 'incremental ability' $(\alpha=.73)$, 'stable ability' $(\alpha=.75)$ and 'specific ability' $(\alpha=.55)$. These factors accounted for 66 per cent of the variance. Given the exploratory nature of the CNAAQ it was decided to keep the 'specific' subscale in for further analysis, despite its low internal consistency, but caution is required in its interpretation.

Positive correlations in theoretically predicted directions were found between the conceptions of 'learning-induced' and 'incremental' $(r=.47)$; between 'gift-induced' with 'stable' $(r=.54)$; and 'general' $(r=.23)$. Negative correlations between 'learninginduced' and 'stable' $(r=-.31)$; 'stable' and 'incremental' $(r=-.35)$; 'general' and 'specific' $(r=-.34)$; and 'incremental' and 'gift-induced' $(r=-.19)$ were also in the expected directions.

\section{Subscale descriptive statistics}

Descriptive statistics for each subscale are presented in Table 2 . The only significant gender difference showed that boys scored higher in the social comparison goal but lower in the mastery goal compared to girls. The group as a whole showed a marked tendency to be orientated towards mastery over social comparison. Similarly, the pupils held weak beliefs for 'stable ability' in comparison to the other five conceptions of ability. The three

Table 2. Descriptive statistics from Study 2

\begin{tabular}{|c|c|c|c|c|c|c|}
\hline & \multicolumn{2}{|c|}{ All $(N=304)$} & \multicolumn{2}{|c|}{ Male $(N=120)$} & \multicolumn{2}{|c|}{ Female $(N=184)$} \\
\hline & Mean & $\mathrm{SD}$ & Mean & SD & Mean & $\mathrm{SD}$ \\
\hline \multicolumn{7}{|l|}{ Goals: } \\
\hline \multicolumn{7}{|l|}{ Social } \\
\hline comparison & 3.04 & 1.03 & 3.26 & 0.98 & 2.90 & $1.04 *$ \\
\hline Mastery & 4.52 & 0.50 & 4.44 & 0.57 & 4.58 & $0.44 *$ \\
\hline \multicolumn{7}{|l|}{$\begin{array}{l}\text { Conceptions of } \\
\text { sport ability: }\end{array}$} \\
\hline Stable & 1.92 & 0.78 & 1.89 & 0.76 & 1.92 & 0.80 \\
\hline Incremental & 4.18 & 0.80 & 4.19 & 0.80 & 4.17 & 0.80 \\
\hline Gift & 2.41 & 1.05 & 2.52 & 1.02 & 2.34 & 1.06 \\
\hline Learning & 4.20 & 0.71 & 4.28 & 0.70 & 4.15 & 0.71 \\
\hline General & 2.12 & 0.94 & 2.15 & 0.95 & 2.11 & 0.94 \\
\hline Sprecific & 4.14 & 0.73 & 4.05 & 0.76 & 4.20 & 0.70 \\
\hline
\end{tabular}

strongest conceptions were incremental', 'specific' and 'learning-induced'. Given the small gender differences noted, data were combined across the two gender groups for all further analyses. Similarly, no differences were found between any of the ages (11-17 years) across any CNAAQ subscale.

\section{Relationships between goals and conceptions of athletic ability}

Results confirmed small but significant positive correlations between the social comparison goal and conceptions of sport ability as stable, natural gift and general, and between the mastery goal and incremental, learning and specific conceptions. The mastery goal was also negatively correlated with stable and gift conceptions (see Table 3).

To determine the multivariate relationship between goals and conceptions of ability, canonical correlation was employed. As shown in Table 4, two significant functions emerged, with the first showing that a strong orientation toward the mastery goal was positively associated with incremental and learning beliefs, and negatively related to

Table 3. Intercorrelations between goal orientations and conceptions of the nature of sport ability (Study 2)

\begin{tabular}{lcc}
\hline Conceptions of the & Social comparison & \\
nature of sport ability & goal & Mastery goal \\
Stable & $.14^{* *}$ & $-.30^{* * *}$ \\
Incremental & .01 & $.36^{* * *}$ \\
Gift & $.26^{* * *}$ & $-.17^{* *}$ \\
Learning & -.01 & $.38^{* * *}$ \\
General & $.15^{* *}$ & -.04 \\
Specific & -.03 & $.14^{*}$ \\
\hline
\end{tabular}

$* p<.05 ; * * p<.01 ; * * * p<.001$.

Table 4. Standardized canonical correlation coefficients for goal orientations and conceptions of the nature of sport ability subscales (Study 2)

\begin{tabular}{lcc}
\hline & Function 1 & Function 2 \\
Goals & & \\
Mastery & 1.00 & -.12 \\
Social comparison & -.03 & -1.00 \\
CNAAQ subscales & & \\
Stable & -.33 & .02 \\
Incremental & .40 & -.21 \\
Gift & -.07 & -.86 \\
Learning & .49 & -.15 \\
General & .09 & -.42 \\
Specific & .26 & -.21 \\
\hline
\end{tabular}


stable beliefs. In contrast, the second function showed that a strong emphasis on social comparison is associated with gift and general beliefs. Canonical redundancy analysis showed that 15.3 per cent of the variance in CNAAQ scores was explained by goal orientations.

\section{Comparison between goal profiles}

Achievement goal orientations have been shown to be orthogonal in several studies of mastery and social comparison goals in sport and exercise contexts (Fox et al., 1994; Goudas et al., 1994), and this was also true in the present study. Consequently, it seems appropriate to examine the different conceptions of athletic ability in relation to 'goal profiles' (see Fox et al., 1994). In order to define the groupings, we used the percentile distribution for each of the mastery and social comparison goal orientations. Thus, a participant scoring in the top third of one orientation was classified 'high', and 'low' when in the lower third. On the basis of this classification, which is more stringent than that used for similar analyses (see Fox et al., 1994; Goudas et al., 1994), four goal groups were identified: low social comparison, low mastery (lo-sc/lo-m; $N=22$ ); low social comparison, high mastery (lo-sc/hi-m; $N=32$ ); high social comparison, low mastery (hi-sc/lo-m; $N=29$ ) and high social comparison, high mastery (hi-sc/hi-m; $N=27$ ).

Results were analysed using a one-way MANOVA, with the four goal groups as the independent variable and the six ability conceptions as dependent variables. This form of analysis was chosen so as to test the profiles of intact groups (Fox et al., 1994) and is deemed superior to tests of independent effects of goals which, as we have argued, are orthogonal.

There was a significant multivariate effect for goal groups (Pillais' trace $=.401$, $F=2.65, p<.0005)$. Post hoc ANOVA procedures revealed significant differences between the goal groups for the incremental, learning-induced and gift-induced ability conceptions (see Table 5). Post boc Scheffé analysis showed significant differentiation between the two low mastery groups and the two high mastery groups on incremental and learning-induced conceptions. The low mastery pupils, regardless of their orientation in

Table 5. Profiles of conceptions of sport ability across the four goal groups (Study 2 means)

\begin{tabular}{|c|c|c|c|c|c|}
\hline & $\begin{array}{l}\text { Lo-sc/lo-ma } a_{\mathfrak{a}} \\
\qquad N=22\end{array}$ & $\begin{array}{l}\text { Lo-sc/hi-ma }{ }_{b} \\
\quad N=32\end{array}$ & $\begin{array}{c}\mathrm{Hi}-\mathrm{sc} / \mathrm{lo}-\mathrm{ma}_{\mathrm{c}} \\
N=29\end{array}$ & $\begin{array}{l}\mathrm{Hi}-\mathrm{sc} / \mathrm{hi}-\mathrm{ma}_{\mathrm{d}} \\
\quad N=27\end{array}$ & $F(3,106)$ \\
\hline Stable & 2.24 & 1.64 & 2.06 & 1.91 & $2.35 * *$ \\
\hline Incremental & $3.76_{\mathrm{bd}}$ & $4.41_{\mathrm{ac}}$ & $3.90_{\mathrm{bd}}$ & $4.40_{\mathrm{ac}}$ & $4.92 * * *$ \\
\hline Gift & $2.53 \mathrm{~b}$ & $1.66_{\mathrm{acd}}$ & $2.61_{\mathrm{b}}$ & $2.77_{\mathrm{b}}$ & $6.75 * * *$ \\
\hline Learning & $3.82_{\mathrm{bd}}$ & $4.46_{\mathrm{ac}}$ & $3.87_{\mathrm{bd}}$ & $4.45_{\mathrm{ac}}$ & $6.19 * * *$ \\
\hline General & 1.94 & 1.66 & 2.23 & 2.11 & $2.30 * *$ \\
\hline Specific & 4.06 & 4.43 & 4.08 & 4.37 & $2.12 *$ \\
\hline
\end{tabular}

Notes. $\mathrm{Lo}=$ low; hi $=$ high; $\mathrm{sc}=$ social comparison; $\mathrm{ma}=$ mastery. Sulscripts $\mathrm{nt} \times \mathrm{xt}$ 10 mean scores correspond to significant group differences (pust boc Scheffé). $* p=.1 ; * * p<.01 ; * * * p<.001$

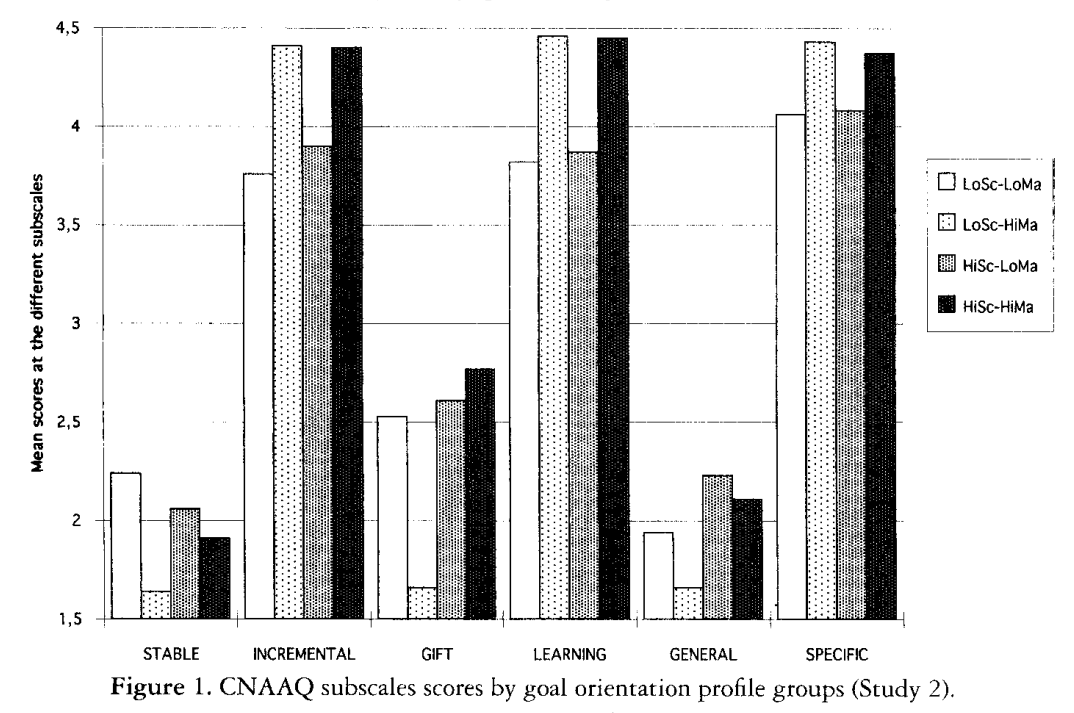

terms of social comparison, showed weaker beliefs in the incremental and learning induced nature of sport ability (see Fig. 1). On the other hand, the lo-sc/hi-m group, in comparison with the other three groups, did not believe as strongly in the gift-induced conception of sport ability. This same trend can also be observed in the stable conception of athletic ability $(p=.076)$. Two other trends can be noted: the two high social comparison groups had higher scores on the general conception of ability $(p=.082)$, while the two high mastery groups showed a preference for the specific conception of ability $(p=.10)$.

In conclusion, this study has shown that conceptions of sport ability are related to achievement goal orientations, and that, in combination, these variables suggest that children and youth may hold 'theories' of goals and beliefs (see Nicholls' [1992] discussion of 'lay achievement theories'). The study has also shown that differences in conceptions of ability are evident for groups classified on the basis of mastery and social comparison goals in combination.

\section{GENERAL DISCUSSION}

The purpose of this research was to investigate the relationship between achievement goal orientations and conceptions of sport ability in children and youth using a social cognitive approach (Fiske \& Taylor, 1991).

The first study used methods described by Dweck \& Leggett (1988). However, the results showed that sport ability, operationally defined simply as a bipolar scale of incremental/fixed beliefs, was not strongly related to goals, although differences between children choosing one goal over another were observed. The results, while partly supportive of those reported by Dweck \& Leggett (1988) in classroom environments, were not as strong as Dweck \& Leggett's. However, when correlation analysis was used for both task and ego goals, relationships were very weak or nonexistent. 
When a more differentiated view of sport ability was adopted, based on scientific and lay analyses in motor learning and performance, the results were much stronger. First, the boys and girls in the second study appeared on the whole to be mastery oriented, and a majority opted for incremental, specific and learning-induced conceptions of athletic ability. These strong representations of the nature of athletic ability, dominated by belief in 'the power of learning' (Durand \& Cailton, 1991), strike us as being linked to prevalent scholastic values. Indeed schools and teachers often emphasize the role of effort (Covington \& Omelich, 1979) and learning in building competence.

Study 2, therefore, has shown important links between different individual goal orientations and conceptions of the nature of athletic ability. Results revealed a positive relationship between the social comparison goal and the view that athletic ability is the product of being a natural gift, and is general. The relationship was also positive between the mastery goal and conceptions of ability being incremental and determined by learning. Furthermore, a mastery orientation showed a negative relationship with the stable conception. These data provide support for our hypotheses.

Analysis of representations of ability in terms of contrasting motivational goal profiles showed similar patterns. Indeed, Fig. 1 shows the incremental, learning-induced and specific conceptions to be homogeneously distributed between the four groups. Independent of the social comparison goal, the two strongly mastery oriented groups were set apart from the two with weak mastery orientation by their greater belief in incremental and learning-induced athletic ability. This pattern could also be traced, albeit rather less convincingly, as far as the specific conception was concerned. A second pattern involved the low social comparison/high mastery goal group who showed a stronger rejection of the gift-induced conception than others. In other words, the mastery goal seems to tie in with the incremental and learning-induced conceptions, whatever the orientation to social comparison may be, thus confirming the results of the canonical analysis. On the other hand, the social comparison group apparently has a greater belief in the determining effect of the 'natural gift' approach to athletic ability, especially when compared with the low social comparison/high mastery group. It should be noted, however, that this same belief is also shared by the two groups that are weakly oriented to both goals.

Finally, the high mastery/high social comparison group is characterized by 'joint conceptions' of ability. This profile, typical of the athletic élite (Famose, Cury \& Sarrazin, 1992), views ability as incremental and determined by both learning and as a natural gift, and this is the representation closest to the scientific analysis of Ackerman (1990) and Fleishman (1964). It would be interesting, therefore, for future studies to examine the conceptions of ability in terms of participants' expertise or sport involvement. The present studies did not have data to test this.

The links between goal orientation and conceptions of athletic ability can partly be explained in terms of the cognitive processes underlying the goals. Indeed, pursuing a mastery or learning goal amounts to admitting that attempted success is under one's personal control (Duda \& Nicholls, 1992; Duda et al., 1992; Nicholls, 1989). It is therefore not surprising that such a representation of success should link with a conception of ability as incremental and essentially work and learning induced. On the other hand, seeking to demonstrate one's superiority over others involves evaluation of one's performance based on external normative criteria (Nicholls, 1984, 1989). Should it become a matter of unceasing concern, with strong emotional repercussions (Jagacinski \& Nicholls, 1984), this could easily foster a stable, gift-determined conception of ability. Wanting to demonstrate competence by using the most differentiated conception of ability means downgrading the role of work and effort. Indeed, for equal performance, ability is judged all the higher when effort is low (Nicholls, 1984, 1989). This goal, therefore, is less compatible with incremental, learning and effort determined representations of ability. Moreover, the social comparison goal has been associated with the belief that athletic suc cess demands high aptitude and the use of illicit or deceptive techniques (Duda \& Nicholls, 1992; Duda et al., 1992). It seems to us that these criteria that are either external (i.e. use of deceptive techniques, possessing special sports equipment etc.), or are internal but not directly controllable (i.e. aptitudes), correspond to the dominant conceptions of athletic ability that characterize social comprespond to the dominant conStudy 2, that is, a stronger emphasis on the staberticints ability as something stable, general, gift-induced conception of Conversemething one has, or does not have, in oneself.

Conversely, it is also possible, as Dweck does (Dweck \& Bempechat, 1983; Dweck \& Elliott, 1983; Dweck \& Leggett, 1988), to conceive of a direction of influence from conceptions of ability to goal orientations. The 'optimistic' representation of incremental ability, specific to a certain field and linked to learning, is a greater incentive to the pursuit of a mastery goal than the belief that ability is stable, general and gift induced. On the other hand, the latter representation of ability is more compatible with a social comparison goal. Seeing ability as a stable entity, general, and linked to built-in aptitude, means subordinating perception of competence to a process of social comparison. Then, indeed, the pursuit of a learning goal becomes pointless, since work is perceived as ineffectual in improving ability.

The relationships between ability conceptions and goals may not be immutable. Representation of ability can readily be seen as developmental over time according to the subject's experience. For example, a child may, despite strenuous effort, see that improvement in ability remains slight, and could then adopt a stable, gift-induced conception of ability. It can also vary depending on the very nature of the athletic activity. Ability in some individual sports, it could be argued, is more easily conceived as basic and limited by genetic aptitude than in some team sports where numerous abilities have to be coordinated and where strategy plays a key role (Sarrazin, Cury \& Famose, 1993).

This evolutionary representation of ability is also consistent with variations in the choice of achievement goal. More precisely, it is not unreasonable to think that, in achievement situations such as sport or school, those individuals who perceive substantial progress in their ability level will have a preference for a mastery goal. On the contrary, as soon as progress slows or stops altogether, children concerned with demonstrating competence are faced with an alternative. Either they decide to avoid work, since it no longer allows them to experience feelings of (self-referenced) competence or, if perceived ability is high enough, they decide to give preference to a social comparison goal which may allow them to demonstrate (normative) competence and thereby to experience further gratification. On the contrary, a stable, gift-induced representation, associated with a low perceived ability, could tie in with weakening achievement motivation, resulting in a weak orientation to both mastery and social comparison goals. In the research reported here, we have found a belief in stable and innate ability in the low social comparison/low mastery group. By measuring perceived ability, other studies might or might not confirm
the above. 
Beyond the links that unite goals and conceptions of ability, the motivational repercussions of such beliefs are fundamental. Believing that being gifted is necessary to succeed (as children do who have a strong social comparison goal) may have adverse consequences for involvement and perseverance. When the subject perceives no particular natural aptitude for an activity, there is the risk of motivational deficits and lack of involvement, similar to a form of learned helplessness. This is also consistent with attributional theories in relating stable attributions for negative events to low expectations of success (Weiner, 1986). In an earlier study, we showed that an activity was less attractive when its success was linked to a gift-induced ability conception rather than to learning, and all the more so when perceived ability in the activity was low (Sarrazin, Cury \& Famose, 1993). Thinking that talent is the major cause of achievement can lead subjects who question their own competence to give up (Nicholls, 1989). Similarly, when ability is perceived as relatively stable or not open to much improvement, the consequences are also detrimental to initial and/or continued involvement (Sarrazin, Cury \& Famose, 1993).

The motivational consequences of the concepts under discussion could also be considered in two further directions. First, there is evidence that situational or social cues can create mastery or performance 'climates' in sport groups (see Biddle, Cury, Goudas, Sarrazin, Famose \& Durand, 1995), thus suggesting that teachers and coaches are in a position to influence the dominant achievement ethos. Second, the creation of motivationally adaptive beliefs and goals may stem from parental influence. Although we have suggested with the data presented that certain goals and beliefs are interrelated, we are not in a position to ascertain how such beliefs have been developed. The role of parental influence, and other socialization factors, is a priority for further study.

The importance of goal orientations is rarely questioned in present studies stemming from achievement motivation research using a social cognitive perspective. In the presen studies we have defined relations between goals and more fundamental representations of the nature of athletic or sport ability. However, further research seems to be in order, such as the need to study the meaning of the causal links between goals and ability conceptions, the influence of expertise or perceived ability, and the evolution of these conceptions in relation to experience or to particular sport activities. Such research is likely to allow for a better understanding of the processes and mediating variables that determine children's motivation for sport.

\section{Acknowledgements}

Parts of this research were supported by grants from the University of Exeter's School of Education Research Fund and the Northoott Devon Medical Foundation.

\section{References}

Ackerman, P. L (1990). A correlational analysis of skill specificity: Learning, abilities and individual differences. Journal of Experimental Psychology: Learning, Memory and Cognition, 5, 883-901.

ences. Journal of Experimental Psychology: Learning, Memory and Cognitton, 5, 883-901.
Biddle, S. J. H., Akande, A., Vlachopoulos, S. \& Fox, K. R. (in press). Towards an understanding of children's mocivation for physical activity: Achievement goal orientations, beliefs about sport success, and sport emomotivation for physical activity: Achievement goal or
tion in Zimbabwean children. Psychollugy and Health.
Biddle, S. J. H., Cury, F., Goudas, M., Sartazin, P., Famose, J-P. \& Durand, M. (1995). Development of scales to measure perceived physical education class climate: A cross-national project. British Journal of Educational Psychology, 65, 341-358.

Burton, D. \& Martens, R. (1986). Pinned by their own goals: An exploratory investigation into why kids drop out of wrestling. Journal of Sport Psychology, 8, 183-197.

Covington, M. V. \& Omelich, C. L. (1979). It's best to be able and virtuous too: Student and teacher evaluative response to successful effort. Journal of Educational Psychology, 71, 688-700.

Duda, J. L. (1992). Motivation in sport settings: A goal perspective approach. In G. C. Roberts (Ed.), Motivation in Sport and Exercise, pp. 57-91. Champaign, IL: Human Kinetics.

Duda, J. L., Fox, K. R., Biddle, S. J. H. \& Armstrong, N. (1992). Children's achievement goals and beliefs about success in sport. British Journal of Educational Psychology, 62, 313-323.

Duda, J. L. \& Nicholls, J. G. (1992). Dimensions of achievement motivation in schoolwork and sport. Journal of Educutionul Psycbolugy. 84, 290-299.

Durand, M. \& Cailton, A. I. (1991). Développement des conceptions de la compétence physique chez des sujets de 7 à 18 ans. In M. Laurent, J. F. Marini, R. Pfister et P. Therme (Eds), Recherche en A.P.S. 3, pP. 319.325. Pars. Actin Universite Aix-Marselle II (UTRSTAPS).

Durand, M., Cury, F., Sarrazin, P. \& Famose, J. P. (in press). Le questionnaire de perception du succès en sport: Validation Francaise du 'Perception of Success Questionnaire'. International Journal of Sport. Psychology.

Dweck, C. S. (1986). Motivarional processes affecting learning. American Psychologist, 41, 1040-1048

Dweck, C. S. \& Bempechat, J. (1983). Children's theories of intelligence. In S. Paris, G. Olsen \& H. Stevenson (Eds), Learning and Motivation in the Classrom, pp. 239-256. Hillsdale, NJ: Erlbaum.

Dweck, C. S. \& Elliott, E. S. (1983). Achievement motivation. In P. H. Mussen (Gen. Ed.) \& E. M Hetherington (Vol. Ed.), Handhosk of Child Psychology: Social and Personality Development, pp. 643-691. New York: Wiley.

Dweck, C. S. \& Henderson, V. L. (no date). Theories of intelligence: Background and measures. Unpublished manuscript, Department of Psychology, University of Illinois.

Dweck, C. S. \& Leggett, E. L. (1988). A social-cognitive approach to motivation and personality. Psychological Revieu, 95, 256-273.

Elliott, E. S. \& Dweck, C. S. (1988). Goals: An approach to motivation and achievement. Journal of Personalit) and Social Psychology, 54, 5-12.

Famose, J. P. (1990). Apprentissage mateur et difficulté de la tache. Paris: INSEP

Famose, J. P. (1991). Rôle des représentations cognitives de la difficulté de la tâche et de l'habileté du sujet dans la motivation à apprendre. In J. P. Famose, P. Fleurance \& Y. Touchard (Eds), L'apprentissage moteur rồt des représentations, pp. 97-118. Paris: Revue EPS.

Famose, J. P., Cury, F. \& Sarrazin, P. (1992). Buts d'accomplissement en fonction du sexe, du lieu de pratique et du niveau de performance. In M. Laurent, J. F. Marini, R. Pfister \& P. Terme (Eds), Les performances motrices. Paris: Edition Actio.

Famose, J. P. \& Durand, M. (1988). Aptitudes et performance motrice. Paris: Revue EPS.

Famose, J. P., Sarrazin, P. \& Cury, F. (1993). Influence des buts d'accomplissement et de l'babileté pergye sur l'effort consenti dans la réalisation d'une tấche. Caen, France: Vèmes Journées Internationales d'Automne de l'A.C.A.P.S.

Famose, J. P., Sarrazin, P., Cury, F. \& Durand, M. (1993). Study of the effects of perceived ability, motivational goal and competitive context upon the selection of task difficulty in a free choice situation. Paper presented at 8th World Congress of Sport Psychology, Lisbon.

Fiske, S. T. \& Taylor, S. E. (1991). Sucial Cognition. New York: McGraw-Hill.

Fleishman, E. A. (1964). Structure and Measurement of Physical Fitness. Englewood Cliffs : Prentice-Hall.

Fox, K. R., Goudas, M., Biddle, S. J. H., Duda, J. L. \& Armstrong, N. (1994). Children's task and ego goal profiles in sport. British Journal of Educational Psychology, 64, 253-261.

Goudas, M., Biddle, S. J. H. \& Fox, K. R. (1994). Achievement goal orientations and intrinsic motivation in physical fitness testing with children. Pediatric Exercise Science, 6, 159-167.

Gould, D., Feltz, D., Horn, T. \& Weiss, M. (1982). Reasons for sport attrition in competitive youth swimming. Journal of Sport Behavior $5,155-165$.

Jagacinski, C. M. \& Nicholls, J. G. (1984). Conceptions of ability and related affects in task involvement and

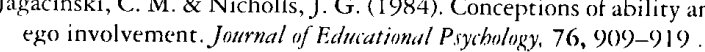


Nicholls, J. G. (1984). Achievement motivation : Conceptions of ability, subjective experience, task choice, and performance. Psychological Review; 91, 328-346.

Nicholls, J. G. (1989). The Competitive Ethos and Democratic Education. Cambridge, MA: Harvard University Press.

Nicholls, J. G. (1992). The general and the specific in the development and expression of achievement motivation. In G. C. Roberts (Ed.), Motivation in Sport and Exercise, pp. 31-56. Champaign, IL: Human Kinetics, Nicholls, J. G. \& Miller, A. T. (1984). Development and its discontents: The differentiation of the concept of ability. In J. Nicholls (Ed.), Advances in Motivation and Achievement: 3. The Development of Achievement Motivation, pp. 185-218. Greenwich, CT: JAI Press.

Nicholls, J. G, Patashnick, M. \& Mettetal, G. (1986). Conceptions of ability and intelligence. Child Development, 57, 636-645.

Roberts, G. C. (1992). Motivation in sport and exercise: Conceprual constraints and convergence. In G. C. Roberts (Ed.), Motivation in Sport and Exerise, pp. 3-29. Champaign, IL: Human Kinetics.

Roberts, G. C. \& Balague, G. (1989). The development of a social cognitive scale of morivation. Paper presented at the 7 th World Congress of Sport Psychology, Singapore.

Roberts, G. C K Kleiber, D. A \& Duda J. L (1981) An analysis of motivation in children's sport: The role of perceived competence in participation. Journal of Sport Psycbology, 3, 206-216.

Sarrazin, P. Cury, E. \& Famose J. P. (1993) Repromtations sur la nature des habiles

Sarrazin, P., Cury, F. \& Famose, J. P. (1993). Representations sur la nature des habiletés sponture
France: Vèmes Journées Internationales d'Auromne de l'A.C.A.P.S.
Schmidt, R. A. (1982). Motor Control and Learning. Champaign, IL: Human Kinetics.

Schmidt, R. A. (1982). Motor Control and Learning. Champaign, IL: Human Kinetics.

Treasure, D. C. \& Roberts, G. C. (1994). Cognitive and affective concomitants of task and

tions dur C Re

Received 23 May 1994: revised version received 15 March 1995 